\title{
TREND ANALISIS PENINGKATAN JUMLAH KUNJUNGAN PASIEN DITINJAU DARI MARKETING MIX
}

\author{
Trend Analysis of Improving The Number of Visitors Patients Reviewed From \\ Marketing Mix \\ Ratna Wardani \\ Dosen Program StudiIlmuKesehatanMasyarakatSTIKes Surya MitraHusada Kediri \\ Ratnawardani1978@yahoo.com
}

\begin{abstract}
Increase in human populations and the state of the economy more advanced, impact public awareness of increasing health.This provides a result to increase in the number of visitors in hospital.The purpose of this research is to analyze increasing trend the number of patient visits in terms of marketing mix done Hospital HVA Toeloengredjo. This research using design descriptive with research analysis using time series with a moving average model arima.Observational research method, with the subject is officer medical record and marketing officer, as well as its object was data on the number of patient visits new and old patient.Testing model results got that model ARIMA(1,1,0) is a model that could be used to perform a forecast or estimate.A prediction visitors keeps increasing, where a prediction the number of visits all patients on the moon 60th (december 2016) is 10746 visits, a prediction the number of visits new patients is 1660 visits, a prediction the number of patient visits long been 9290 visits .
\end{abstract}

Keywords : Time series, Visits , ARIM

\begin{abstract}
Abstrak
Bertambahnya populasi manusia dan keadaanperekonomian yang semakinmaju, berdampakkesadaranmasyarakatterhadapkesehatansemakin inimemberikanakibatkepadapeningkatanjumlahpengunjungdi rumahsakit.Tujuandaripenelitianiniadalahuntukmenganalisistrendpeningkatanjumlahkun junganpasien ditinjau dari marketing mix yang dilakukanRumahSakit HVA Toeloengredjo.Penelitianinimenggunakandesainpenelitiandeskriptifdengananalisistime series menggunakan moving average dengan model ARIMA. Metode penelitian observasional, dengan subjek adalah petugas rekam medik dan petugas pemasaran, serta objeknya adalah data jumlahkunjunganpasienbarudanpasien lama. Hasil pengujian model didapatkan bahwa model ARIMA $(1,1,0)$ adalah model yang bisa digunakanuntukmelakukansuatuprediksiatauperkiraan.Prediksipengunjungterusmengala mi kenaikan, dimana prediksi jumlah kunjungan seluruh pasien pada bulan ke-60 (Desember 2016) adalah 10746 kunjungan,Prediksijumlahkunjungan pasien baruadalah 1660 kunjungan,prediksijumlahkunjunganpasien lama adalah 9290 kunjungan.
\end{abstract}

Kata Kunci :Time series, Kunjungan, ARIMA

Ratna Wardaniadalah Bagian Dosen Program StudiI Imu Kesehatan Masyarakat STIKes Surya MitraHusada Kediri 


\section{PENDAHULUAN}

Seiring perkembangan zaman, rumah sakit saat ini tengah dihadapkan dengan era persaingan global diberbagai sektor kesehatan.Keberadaan rumah sakit mutlak diperlukan karena setiap orang yang mengalami gangguan kesehatan pasti membutuhkan pengobatan dan salah satu penyedia layanan kesehatan adalah rumah sakit.Seiring dengan bertambahnya populasi manusia dan keadaan perekonomian yang semakin maju, maka kesadaran masyarakat terhadap kesehatan semakin meningkat.Hal ini dapat meningkatkan jumlah pengunjung rumah sakit.Pihak rumah sakit harus menambah kapasitas terhadap fasiltasfasilitas yang ada.Selain penambahan kapasitas, pihak rumah sakit juga harus meningkatkan kualitas pelayanan yang diberikan. Hal ini bertujuan agar proses penanganan pasien bisa berjalan dengan cepat dan pasien dapat terlayani dengan baik.

Banyak faktor yang dapat menyebabkan terjadinya angka peningkatan dan penurunan jumlah kunjungan pasien di Rumah Sakit.Faktorfaktor demografis seperti pertumbuhan jumlah penduduk, tingkat pendapatan, promosi, persepsi tarif, mutupelayanan, persepsisakit, pengalamansakit.

$$
\text { Salah satuusaha yang }
$$

dapatdilakukanuntukpeningkatanjumlah pasienadalahdenganmelakukanpemasar an.DepartemenpemasaranRumahSakit HVA

Toeloengredjotelahmelakukanupayape masaranyaituberupamelakukanpendeka tandenganparatokohmasyarakat,

paramedis, instansi, daninstitusipemerintahan, selainitudenganmelakukanpromosimelal ui media advertising di suratkabarharian, radio lokal, brosurdan banner yang diletakan di tempatstrategis. Rumahsakit HVA Toeloengredjojugamenjadi sponsor diberbagaiacarakesehatan yang dilakukanolehinstitusipemerintahandan swasta.

Berdasarkan data rekammedis jumlah kunjungan pasien rawat jalan dan rawat inap di Rumah Sakit HVA Toeloengredjo mengalami peningkatan dan penurunan setiap bulannya. Pada tahun 2013 jumlah total kunjungan pasiennya 61196, dan sampai bulan september pada tahun 2015 jumlah total

kunjunganpasiennya86643.Tujuandarip enelitianiniadalahuntukmenganalisistre ndpeningkatanjumlahkunjunganpasiend itinjaudarimarketing mix yang dilakukanRumahSakit HVA ToeloengredjosehinggaRumahSakit HVA Toeloengredjobiasmelakukanpersiapanp enambahanfasilitasdankapasitas.

\section{METODE}

Penelitian ini adalah deskriptif dengan pendekatan time series. Metode penelitian observasional, dengan subjek adalah petugas rekam medik dan petugas pemasaran, serta objeknya adalah data sekunderjumlahkunjunganpasienbaruda npasien lama tahun 2012- September 2015.

Ujistatistik yang digunakan adalah analisis time series dengan metode autoregressive integrated moving average (ARIMA). 


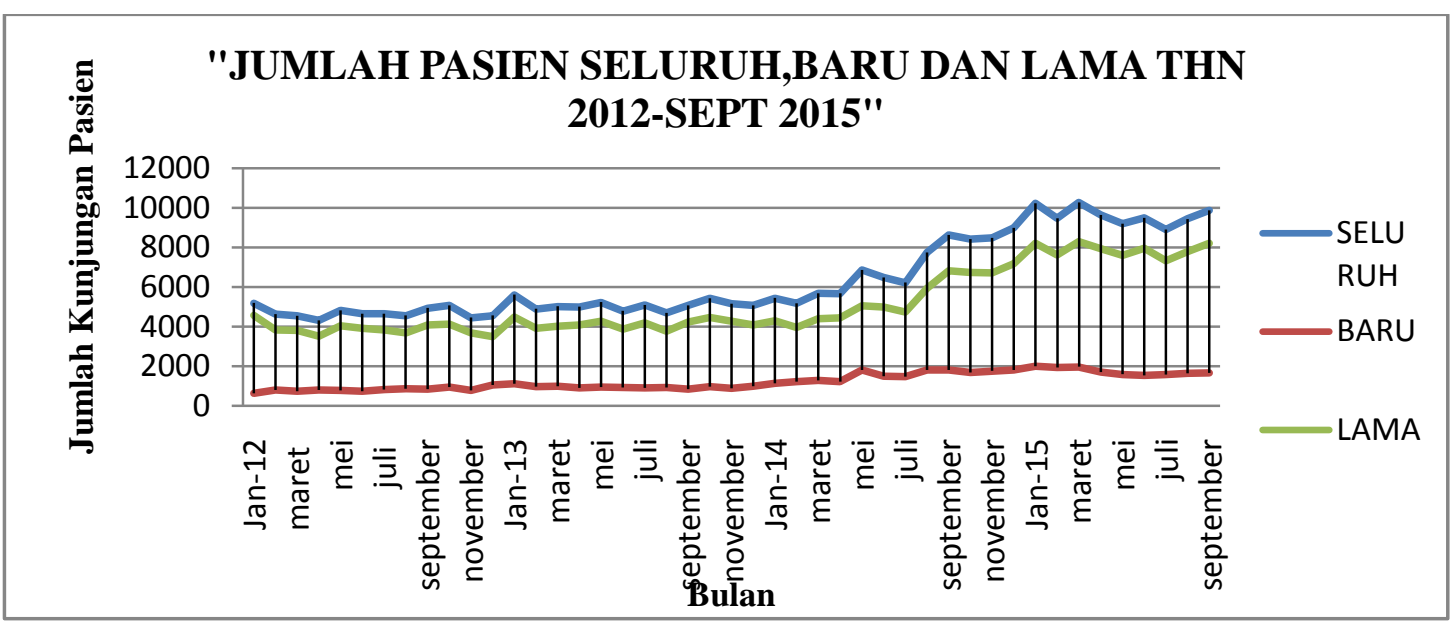

Gambar 1.Jumlahpasienseluruh, lama danbaru

\section{HASIL DAN PEMBAHASAN}

\section{Jumlah Kunjungan Pasien}

Data jumlah kunjungan pasien lama Rumah Sakit HVA ToeloengredjoPare januari 2012 sampai dengan september 2015, kunjungan pasien tertinggi terjadi pada bulan Maret 2015 dengan jumlah kunjungan mencapai 8293 pasien, dan kunjungan terendah yaitu pada bulan Desember 2012 yakni 3503 pasien lama.

Data jumlah kunjungan pasien baru Rumah Sakit HVA ToeloengredjoPare januari 2012 sampai dengan september 2015, kunjungan pasien tertinggi terjadi pada bulan Januari 2015 dengan jumlah kunjungan mencapai 2010 pasien, dan kunjungan terendah yaitu pada bulan Januari 2012 yakni 637 pasien baru.

Data jumlah kunjungan pasien Rumah Sakit HVA Toeloengredjo Pare januari 2012 sampai dengan september 2015, kunjungan

tertinggiterjadipadabulan Maret 2015 yakni sebesar 10270 kunjungan dan terendah pada bulan April 2012 yakni 4331. Naiknya jumlah kunjungan pasien di Rumah Sakit HVA Toeloengredjo perbulan disebabkan karena kunjungan pasien lama dengan rata-rata 5170, sedangkan kunjung pasien baru dengan rata-rata 1237 kunjungan. (Lihat Gambar 1).

\section{Marketing mix}

Promosi yang dilakukan Rumah Sakit HVA Toeloengredjo sangat beragam mulai dari pendekatan dengan tokoh masyarakat, paramedis, iklan di Radio setiap hari Sabtu, surat kabar di Jawa Pos, pembuatan banner dan brosur, mengadakan seminar kedokteran, kebidananan, dan keperawatan, gathering agen, baksos seperti khitanan massal, pembagian sembako, setiap tahunnya promosi yang dilakukan makin gencar dengan penambahan alat dan fasilitas yang ada di rumah sakit, mengadakan roadshow seminar kesehatan, dan yang terbaru pada tahun 2015 yaitu launching stiker Rumah Sakit HVA dibelakang angkutan umum pare. Produk yang dimiliki Rumah Sakit HVA Toeloengredjo yang menjadi unggulan yaitu hemodialisa, radiologi, beauty SPA, ESWL, CT Scan, Dokter spesialis lengkap, treadmil test, echocardiography, dan fasilitas lainnya yang mendukung seperti penambahan AC di ruang tunggu, melayani pasien BPJS, dan penambahan dokter spesialis.

Untuk meningkatkan sumber daya manusia (people) seperti petugas medis dan non medis Rumah Sakit HVA Toeloengredjo melakukan pelatihan service excellent 1 tahun dilakukan $2 \mathrm{x}$, seminar 
kesehatan, dan melakuakan pelayanan prima.

Tempat (place), pasien Rumah Sakit HVA tidak hanya melayani pasien Pabrik Gula saja, jumlah pasien umum dan BPJS yang berobat ke Rumah sakit HVA juga sangat banyak terutama yang berobat pada dokter spesialis.

Tarif (Price) kamar Rumah Sakit HVA Toeloengredjo tahun 2013 sampai 2014 tidak mengalami kenaikan tarif, hanya pada tahun 2015 terjadi kenaiakan sebesar Rp.25.000 diruangan kelas VIP C, Kelas 1, Kelas 2, Kelas 3 dan Isolasi.

\section{AnalisisTrendPeningkatanKunjungan Pasien.}

Hasil prediksianalisis ARIMA $(1,1,0)$ menerangkannilaiprediksiuntuk bulan April 2016 sampai Desember 2016 dimana prediksi jumlah kunjungan seluruh pasien pada bulan Desember 2016 adalah 10746 kunjungan dalam selang kepercayaan 95\% terdapat dalam 4323-17169 kunjungan. (Lihat Tabel 1).

\section{Jumlah Kunjungan pasien}

Jumlah kunjungan pasien di Rumah Sakit HVA Toeloengredjo antara Januari 2012-September 2015 rata-ratanya adalah 6404 kunjungan perbulan.Dilihat dari ratarata jumlah kunjungan pasien mengalami peningkatan baik dari pasien baru dan pasien lama.Namun bila dilihat dari jumlah kunjungan pasien baru dan pasien lama, kunjungan pasien di Rumah Sakit HVA didominasi oleh pasien lama.

Data jumlah kunjungan pasien baru Rumah Sakit HVA ToeloengredjoPare januari 2012 sampai dengan september 2015, kunjungan pasien tertinggi terjadi pada bulan Januari 2015 dengan jumlah kunjungan mencapai 2010 pasien, dan kunjungan terendah yaitu pada bulan Januari 2012 yakni 637 pasien baru.

Tabel 1. TabelPrediksiSeluruhPasien, Pasien lama danpasienbarubulan April 2016Desember 2016

\begin{tabular}{llllllllll}
\hline Bulan & April & Mei & Juni & Juli & $\begin{array}{l}\text { Agustu } \\
\text { s }\end{array}$ & Sept & Okt & Nop & Des \\
\hline Seluruhpasie & 1016 & 1023 & 1031 & 1038 & 10455 & 1052 & 1060 & 1067 & 1074 \\
$\mathrm{n}$ & 4 & 7 & 0 & 2 & & 8 & 0 & 3 & 6 \\
\hline PasienBaru & 1660 & 1660 & 1660 & 1660 & 1660 & 1660 & 1660 & 1660 & 1660 \\
\hline Pasien Lama & 8616 & 8699 & 8783 & 8868 & 8952 & 9037 & 9121 & 9205 & 9290 \\
\hline
\end{tabular}

Data jumlah kunjungan pasien lama Rumah Sakit HVA ToeloengredjoPare januari 2012 sampai dengan september 2015, kunjungan pasien tertinggi terjadi pada bulan Maret 2015 dengan jumlah kunjungan mencapai 8293 pasien, dan kunjungan terendah yaitu pada bulan Desember 2012 yakni 3503 pasien lama.

Selain kunjungan pasien lama yang mendominasi, perlu diperhatikan juga peningkatan jumlah pengunjung baru, data jumlah kunjungan pasien baru Rumah Sakit HVA ToeloengredjoPare januari 2012 sampai dengan september 2015, kunjungan pasien tertinggi terjadi pada bulan ke-37 dengan jumlah kunjungan mencapai 2010 pasien, dan kunjungan terendah yaitu pada bulan ke1 yakni 637 pasien baru.

Dahulu Rumah Sakit HVA Toeloengredjo pare dikenal dengan rumah Sakit untuk para karyawan pabrik gula, setelah Rumah Sakit HVA 
toeloengredjo menjadi Rumah Sakit Umumpasien yang datang ke Rumah Sakit HVA toeloengredjo lebih banyak pasien umumnya yaitu dengan perbandingan $70 \%$ pasien umum dan $30 \%$ karyawan pabrik gula. Setelah adanya BPJS di tahun 2014 peningkatan pasien umummenjadi $80 \%$ dan karyawan pabrik gula $20 \%$.

\section{Marketing mix}

Dilihat dari hasil marketing mix yang dilakukan oleh Rumah Sakit HVA Toeloengredjo Peneliti berasumsi banyaknya pasien lama yang loyal terhadap Rumah Sakit HVA Toeloengrejo dikarenakan dari fasilitas dan petugas kesehatan yang dimiliki, dilihat dari jenis penyakit tertinggi di Rumah Sakit HVA Toeloengredjo pada triwulan pertama yaitu januari-maret 2015 yaitu GGK (Gagal Ginjal Kronis) yaitu 1812 penderita di rawat jalan dan 156 penderita rawat inap. Dengan adanya alat Hemodialisa sehingga banyak pasien yang menderita GGK memilih untuk berobat ke Rumah Sakit HVA Toeloengredjo.Peneliti menyarankan untuk dilakukan penelitian lebih lanjut mengenai penyebab naiknya kunjungan pasien lama dan baru ditinjau dari marketing mix.

\section{Analisis Trend Kunjungan Pasien}

Diketahui nilai signifikansi jumlah kunjungan seluruh pasien sebesar 0,519 $(>0,05)$, maka hipotesis nol diterima yang berarti bahwa model ARIMA $(1,1,0)$ adalah model yang biasdigunakanuntukmelakukanprediksi. Hasilanalisisdenganmenggunaka nARIMA

menunjukkannilaiprediksiuntukbulan

April 2016 sampaiDesember 2016 untukjumlahkunjunganseluruhpasien pada bulan Desember 2016 adalah 10746 kunjungan dalam selang kepercayaan 95\% terdapat dalam 432317169 kunjungan.

$$
\text { Dengan }
$$

hasiljumlahprediksikunjunganpasien

yang semakinmeningkat, diharapkandapatmembantu Rumah sakit untuk mempersiapkan menambah fasilitas seperti ruang rawat inap, free wifi diruang tunggu untuk menambah kenyamanan pengunjung, pelayanan prima, penambahan alat-alat kesehatan, penambahan tenaga medis atau non medis dan juga sumber daya yang mendukung untuk menciptakan kepuasaan pasien yang berobat ke Rumah Sakit HVA Toeloengredjo.

\section{SIMPULAN DAN SARAN Simpulan}

Peningkatan jumlah kunjungan pasien dilihat dari jumlah pengunjung baru dan jumlah pengunjung lama yang lebih dominan adalah jumlah pengunjung lama yang menunjukkanbahwapengunjung lama memilikiloyalitasterhadapRumahSakit HVA Toeloengredjo.Naiknya jumlah kunjungan pasien di Rumah Sakit HVA Toeloengredjo perbulan disebabkan karena kunjungan pasien lama dengan rata-rata 5170, sedangkan kunjung pasien baru dengan rata-rata 1237 kunjungan.Rata-rata

jumlahkunjunganbaru yang terus meningkat karena Rumah Sakit HVA Toeloengredjogencarmelakukanpromosi danmeningkatkankualitaspelayanandanf asilitas untuk menunjang kebutuhan pasien.

Marketing mix yang dilakukan untuk meningkatan kunjungan pasien salah satunya yaitu peran produk atau fasilitas pelayanan yang ada di Rumah Sakit HVA Toeloengredjo, dengan adanya 
Hemodialisa.

Berdasarkan hasil analisis time series menggunakan moving average model ARIMA $(1,1,0)$ pengunjung RSHVA Toelongredjoterusmengalamikenaikan.P rediksijumlahkunjunganpasien pada bulan Desember 2016 adalah 10746 kunjungan dalam selang kepercayaan 95\% terdapat dalam 4323-17169 kunjungan.

\section{Saran}

kunjungan

Dengan mengetahui trend pasiendanprediksijumlahpasienkedepan diharapkanpihakrumahsakituntuk mempersiapkan perencanaan kedepannya, seperti penambahan sumber daya manusia, fasilitas ( seperti free wifi di area rumah sakit, penambahan tempat tidur, alat canggih seperti, LINAC, ESMR) dan pelayanan yang lebih baik lagi (service excellent).

Bagipenelitian

yang

akandilakukanselanjutnyadapatdikemba ngkan dengan menggunakan teori-teori yang sudah ada, seperti penyebab naiknya kunjungan pasien lama dan baru ditinjau dari marketing mix.

\section{DAFTAR RUJUKAN}

[1] Alfiati, Y. 2008. Faktor-Faktor Yang Mempengaruhi Pemanfaatan Pelayanan Poli Obgyn Di RSUD Banjarnegara. Jurnal Kesmas UAD.

[2] Anggraeni, W. 2012. Prediksi Jumlah Kunjungan Pasien Rawat Jalan Menggunakan Metode Genetics Fuzzy Systems Studi Kasus Rumah Sakit Usada Sidoarjo. Jurnal Teknik ITS .

a. 2008. Pemanfaatan

Pelayanan Instalasi Rawat Jalan Di Rumah Sakit Umum Indrasari Rengat Dan Puskesmas Pekan Heran Kabupaten Indragiri Hulu. Program Pascasarjana Universitas Gajah Mada.

[4] Hendrik. 2010. Etika \& Hukum Kesehatan. Jakarta: EGC.

[5] Herlambang, S. 2012. Manajemen Kesehatan Dan Rumah Sakit. Yogyakarta: Gosyen Publishing.

[6] Triyono, Joko. 2011. Pemasaran Pelayanan Kesehatan. (http://id.shvoong.com/socialsciences/economics/1805317pemasaran-pelayanan-kesehatan). Diakses tanggal 17 Oktober 2015.

[7] Kemenkes. 2013. Profil Kesehatan Indonesia. Kementrian Kesehatan RI.

[8] Kuswanti, N. D. 2012. Pengaruh Bauran Pemasaran Terhadap Keputusan Pasien Berobat Di Rumah Sakit.FE USU.

[9] Prasko. 2013. Pengertian Hak Dan Kewajiban Pasien. (prasko17.blogspot.com) Diakses tanggal 17 Oktober 2015.

[10] Raykuti, F. 2012. Riset Pemasaran. Jakarta: Gramedia Pustaka Utama.

[11] R.I, Kemenkes. 2013. Profil Kesehatan Indonesia. Kementrian Kesehatan RI .

[12] Sabran. 2014. Evaluasi Bauran Pemasaran Di Rumah Sakit Universitas Hasanudin.

[13] Santosa, D. P. 2005. Analisis Statistik Dengan Microsoft Excel \& SPSS. Semarang: ANDI.

[14] Sugiyono. 2013. Metode Penelitian 15.Manajemen. Bandung: Alfabeta.

[16] Sukardi. 2005. Metode Penelitian Pendidikan. Yogyakarta: Bumi Aksara. 


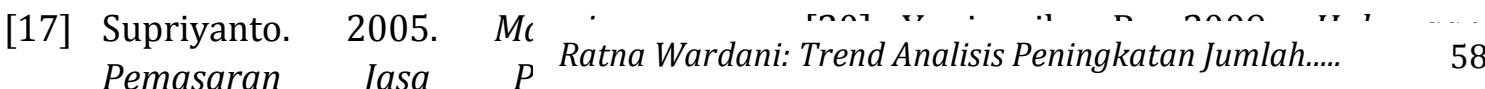
Kesehatan. Surabaya: FKM UNAIR.

[18] Tjiptono, Fandy. 2008. Strategi Pemasaran. Edisi ke 3. Yogyakarta: Andi

[21] Yamin,Sofyan. 2009. Teknik Analisis Statistik Terlengkap dengan Software SPSS. Salemba Infotek

[19] Yulianto. 2012. Analisa Time Series. (https:digensia.wordpress.com) Diakses tanggal 19 Oktober 2015. 